\title{
AS RELAÇÕES DE TRABALHO E A QUESTÃO DE SUA FLEXIBILIZAÇÃO
}

ROCCO ANTONIO RANGEL ROSSO NELSON

INSTITUTO FEDERAL DO RIO GRANDE DO NORTE IFRN, CAMPUS JOÃO CÂMARA

BRASIL

"La socialización sólo se presenta cuando la coexistencia aislada de los individuos adopta formas determinantes de cooperación y colaboración que caen bajo el concepto general de la acción recíproca”. 


\begin{tabular}{c}
\hline $88<\quad$ ROCCO ANTONIO RANGEL ROSSO NELSON \\
AS RELAÇÕES DE TRABALHO E A QUESTÃO DE SUA FLEXIBILIZAÇÃO \\
Pags. $86-101$
\end{tabular}

Recibido: 03/11/2014 Aceptado: 28/04/2015

\title{
RESUMO
}

o se conversar/debater sobre as prerrogativas básicas do trabalhador, não
se tem como esquivar-se sobre a amplitude desses direitos sociais e suas
consequências econômicas no custo de um empreendimento empresarial. Afere-
se que os argumentos sobre a chamada flexibilização/desregulamentação do direito trabalhista têm sua base numa político-econômica neoliberal, o qual propugna por uma norma trabalhista cunhado no seio do "mercado", de sorte que ela se adeque, se amolde, as necessidades e na velocidade da expansão do mesmo. A pesquisa em tela, fazendo uso de uma metodologia de análise qualitativa, usando-se os métodos de abordagem hipotético-dedutivos de caráter descritivo e analítico, tem por linha de fundo analisar a racionalidade do discurso sobre a flexibilização das relações de trabalho.

Palavras-Chave: relação de trabalho, flexibilização, discurso econômico, uma resposta do Direito.

\begin{abstract}
When you talk/discuss the basic prerogatives of the worker, there is no way to dodge on the scale of these social rights and their economic impact on the cost of a business enterprise. Is assessed that the arguments about the so called relaxation/deregulation of labor law has its basis a new liberal political-economic, which advocates for a labor standard coined within the "market", so it fits the requirements and speed of expansion. Research on screen, making use of a method of qualitative analysis, using the methods of hypothetical-deductive approach of descriptive and analytical character, the bottom line is to analyze the rationality of discourse on flexibility of labor relations.
\end{abstract}

Keywords: working relationship, flexibilization, economic discourse, a response of law.

\section{RESUMEN}

Al hablar / discutir las prerrogativas fundamentales de los trabajadores, no hay manera de esquivar considerar la magnitud de estos derechos sociales y su impacto económico en el 
costo de un proyecto empresarial. Puede afirmarse que los argumentos acerca de la llamada flexibilización / desregulación de la legislación laboral tiene su base en una política económica neoliberal, que aboga por una norma laboral acuñada con el sello del "mercado", de modo que ella se ajusta, se amolda a las necesidades y velocidad de expansión del mismo. La presente investigación, haciendo uso de un método de análisis cualitativo, utilizando los métodos de enfoque hipotético-deductivo de enfoque descriptivo y analítico, tiene por línea de fondo analizar la racionalidad del discurso sobre la flexibilización de las relaciones laborales.

Palabras Clave: relación de trabajo, flexibilización, discurso económico, una respuesta del derecho.

\section{DAS CONSIDERAÇÕES INICIAIS}

Desenvolve-se uma discursão, que já atravessa décadas ${ }^{1}$, a qual veio a tomar novo fôlego com a crise financeira do "subprime", nos Estados Unidos, em 2008, da imperiosa necessidade de reforma na legislação trabalhista, principalmente no que tange a figura da Consolidação das Leis do Trabalho, que juntamente com a o plexo de direitos fundamentais sociais previsto da Constituição Federal de 1988, tornam a figura do empregado um custo altíssimo de empresa, o que limita a possibilidade do agente econômico de se adaptar as crises, bem como fazer frente a uma concorrência, o qual não se limita mais ao ambiente de mercado local ou mesmo nacional, mas sim global ${ }^{2}$.

“..., essa renovação tecnológica intensa eliminava as antes impermeáveis barreiras do espaço e do tempo, extremando a competição capitalista no plano das diversas regiões do globo" (Delgado, 2011, p. 99).

As pessoas dispõem agora não apenas de seu próprio sistema de acesso às informações para entender melhor o que está ocorrendo em seus países ou fora dele, não apenas para discuti-las entre si, mas também do mecanismo de comando e controle para se organizar e tomar uma providência', acrescenta Mundie. "No passado, somente governos e exércitos dispunham desses tipos de sistemas de comando e controle. Agora as pessoas dispõem. E quanto mais essas ferramentas penetram em grandes volumes, mais cai o preço de sua produção e uso, e então mais elas penetram e mais longe se difundem. E, quanto mais se difundem, mais

\footnotetext{
${ }^{1}$ Podemos falar que esse debate, no Brasil, começa a se desenvolver, fortemente, a partir da década de 90.

2 "É comum ocorrerem crises, em princípio localizadas, ou restritas à esfera interna de certos países, mas que acabam alcançando outras regiões, todo o território nacional, e mesmo outros Estados nacionais, em curto espaço de tempo". (Garcia, 2013, p. 52)
} 
impossível se torna controlar qualquer coisa do centro”. Mais impossível se torna também manter qualquer coisa no nível "local". Tudo agora flui instantaneamente dos cantos mais remotos de qualquer país para essa plataforma global onde tudo é compartilhado (Friedman \& Mandelbaum, 2012, p. 80).

Além das instabilidades econômicas e do fator concorrência, citado supra, somase ao desenvolvimento tecnológico (robotização, microeletrônica, microinformática, hiperconectividade gerado pela internet ${ }^{3}$, etc), novas formas de organização de produção e o desafio de combater o desemprego/subemprego, dentre outros fatores, vindo à tona o debate sobre a necessidade de flexibilização das relações de trabalho.

Segue as palavras de Barros (2001):

...Muitos sustentavam que a predominância de normas imperativas nos institutos jurídicos era o fato gerador da crise das empresas, uma vez que lhes retirava as possibilidades de adaptarem-se a um mercado turbulento. Afirmavam que a rigidez daí advinda impedia a competitividade das economias europeias e o aproveitamento das oportunidades de inovação tecnológica... (p. 68).

Será mesmo que esse contexto econômico justifica suplantar normas protetivas do trabalho? É o Direito do Trabalho um direito arcaico que entrava o progresso, obstaculizando o crescimento econômico?

Fazendo uso de uma metodologia de análise qualitativa e utilizando-se os métodos de abordagem hipotético-dedutivos de caráter descritivo e analítico, buscar-se-á fazer uma apreciação sobre essa temática.

\section{O DISCURSO PELA FLEXIBILIZAÇÃO DOS DIREITOS TRABALHISTAS}

A partir dessa realidade, galgada pelo dinamismo econômico, ver-se no Direito do Trabalho um empecilho a expansão do capital ${ }^{4} \mathrm{e}$ a livre organização do mercado.

\footnotetext{
3 "Se a Terra Plana 1.0 girava em torno de produzir mercadorias e serviços nessa nova plataforma global, a Terra Plana 2.0 gira em torno de tudo isso - mas também de gerar e compartilhar ideias nessa plataforma. ... o que o PC, a internet e os mecanismos de busca fizeram para as páginas da web 'foi permitir que qualquer pessoa com conectividade achasse qualquer coisa que lhe interessasse', e o que o pc, o smartphone, a internet e o Facebook estão fazendo 'é permitir que qualquer um ache qualquer pessoa' que lhe interesse ...". (Friedman \& Mandelbaum, 2012, p. 80)

4 "A flexibilização tem sido voltada para o capital, para o aumento da produção. Visa maximizar lucros em decorrência da internacionalização das economias" (Martins, 2009, p. 07).
} 
Na verdade, a globalização que nos é oferecida não vem acompanhada de um comportamento liberal ou neoliberal dos países centrais, já que impõem barreiras monetárias e alfandegárias. A alta proteção trabalhista e a visão do bemestar social praticados na era da administração econômica nacional ocasionam sociedades ocidentais não competitivas em relação às economias industrializadas e, por isso, alguns defendem que tais direitos devem ser drasticamente reduzidos, diminuindo os gastos, possibilitando melhor competitividade no mercado (Cassar, 2011, p. 26).

De tal sorte, propaga-se um discurso fervoroso de que a Consolidação das Leis do Trabalho está fora do seu tempo, não sendo mais um uma fonte normativa, a contento ${ }^{5}$, aos anseios desse mercado hiperconectado.

De fato, o ramo justrabalhista afirmou-se no período anterior como o mais clássico e abrangente instrumento de políticas sociais surgido no capitalismo, produzindo inquestionável intervenção normativa na economia, em favor, regra geral, de importante distribuição social dos ganhos do sistema econômico. Nesse contexto, a desregulamentação de suas regras ou, pelo menos, sua crescente flexibilização, tudo passou a compor foco destacado na matriz cultural que se generalizou no Ocidente no último quartel do século XX (Delgado, 2011, p. 99).

Ao contrário, seria o Direito do Trabalho um verdadeiro óbice ao desenvolvimento econômico do Brasil ${ }^{6}$, gerando efeitos deletérios ao próprio trabalhador 7 , visto que em decorrência de fatores econômicos, os empregadores não teriam mobilidade em suprimir direitos dos empregados, os quais foram elevados a status de direito fundamental, o que originaria a demissão do mesmo, em decorrência da impossibilidade de redução do custo com a mão-de-obra.

A quebra dessa rigidez, no que tange a premissas trabalhistas, tem sido denominado de flexibilização do Direito do Trabalho ${ }^{8}$ o qual pode-se dizer que tem o seguinte slogan: “diminuição dos salários em pró da manutenção e criação de vagas de emprego".

\footnotetext{
5 "A legislação trabalhista brasileira pode ser comparada a urna máquina ultrapassada, que foi criada para trabalhar, mas que parecia não ter nascido para semelhante fim. A CLT não tem mais a mesma finalidade que tinha quando de sua criação, necessitando ser revista. Urna das formas dessa revisão é verificar mecanismos de flexibilização, de forma a adaptar à realidade de fato à norma jurídica" (Martins, 2009, p. 02).

6 "Houve, sem dúvida, uma acentuada desregulação, informalização e desorganização do mercado de trabalho, especialmente nos países semiperiféricos ao capitalismo central (Brasil, incluído), porém, sem que se criassem alternativas minimamente civilizadas de gestão trabalhista, em contraponto com o padrão juslaborativo clássico" (Delgado, 2011, p. 990).

7 “Nessa visão, a legislação criada pelo Estado, para proteger o trabalhador representada, em especial, pela Consolidação das Leis do Trabalho, acabar tendo o efeito perverso de, por vezes, retirar-lhe a sua própria fonte de renda, vale dizer, o seu emprego, isto é, a possibilidade de trabalhar para obter o seu sustento" (Garcia, 2013, p. 52).

8 "... seria imperioso flexibilizar as normas que disciplinam as relações de trabalho, possibilitando ao empregador, ao invés de dispensar os empregados, em momentos, por exemplo, de dificuldade financeira, reduzir ou mesmo excluir determinados direitos, que não integrem o núcleo mínimo necessário, ainda que com a participação dos sindicatos das categorias profissionais, de modo a adaptar o Direito do Trabalho à atual situação econômica" (Garcia, 2013, pp. 52-53).
} 
Essa flexibilização dar-se-ia, por exemplo, da seguinte maneira: “... precarização dos contratos, seja através da terceirização, do excesso de trabalho, dos baixos salários, seja através de contratos temporários; e a prevalência contratual sobre a estatutária, enfatizandose o negociado sobre o legislado" (Cassar, 2010, p. 42).

Ao se falar em flexibilização dos direitos trabalhistas, vem acoplado a esse discurso a figura da necessidade da desregulamentação $0^{9}$, onde as normativas trabalhistas ao invés de ser dispostos em enunciados legislativos, onde a rigidez é natural de sua estrutura, passariam a ser frutos de negociações coletivas intermediados pelos sindicatos patronais ou pelo próprio empregador e os sindicatos dos trabalhadores ${ }^{10}$.

Evidencia-se nas relações coletivas de trabalho, que são organizadas através e sindicatos, uma fragilidade em todo o mundo, predominando poder econômico em detrimento de políticas públicas que possam equilibrar as forças do capital e da mão de obra. Aumentam as taxas de desfiliação sindical e os novos operários estão cada vez menos interessados no sindicato que os representam, uma das causas disso é, sem dúvida, decorrente da política neoliberal. O sindicalismo sempre esteve ao lado de posturas socialistas ou comunistas, o que não tais encontra espaço no cenário atual, devido à queda da ideologia soviética (Lebre, 2013, p. 45).

Preciosas são as palavras de Scabin (2013):

"No mundo do trabalho, como consequência dos grandes índices de desemprego, assistirmos ao enfraquecimento das entidades sindicais, constritas agora defesa da manutenção, pelas empresas, das vagas de trabalho. O papel do sindicato, que outrora lutava pela conquista de direitos para os trabalhadores, fica, relegado, no mundo atual, à luta pela diminuição do desemprego" (p. 41).

O atual conjunto normativo, no Brasil, no que tange a flexibilização ${ }^{11}$, possui exemplos dessa reinvindicação empresarial: a figura do regime de tempo parcial (acrescido a Consolidação

\footnotetext{
${ }_{9}^{9}$ Além disso, seria necessário desregulamentar certos aspectos da disciplina legal da relação de emprego, prevista na CLT, os quais passariam a ser regidos por normas decorrentes da negociação coletiva de trabalho" (Garcia, 2013, p. 53).

${ }_{10}$ Pode-se falar em desregulamentação heterônoma, quando realizada unilateralmente pelo Estado, onde estar-se-ia diante de uma flexibilização heterônoma. Bem como existe a figura a desregulamentação fruto das negociações convencionais, as quais substituiriam as garantias legais (flexibilização autônoma) (Barros, 2011).

11 “A flexibilidade interna atinente à ordenação do trabalho na empresa, compreende a mobilidade funcional e geográfica, a modificação substancial das condições de trabalho, do tempo de trabalho, ... flexibilização externa, que diz respeito ao ingresso do trabalhador na empresa, às modalidades de contratação, de duração do contrato, da dissolução do contrato... “ (Barros, 2011, p. 69).
} 
das Leis do trabalho por meio da Medida Provisória $\mathrm{n}^{\mathrm{0}}$ 2.164-41, de 2001) ${ }^{12}$; suspensão do contrato para participação do empregado curso ou programa de qualificação profissional oferecido pelo empregador (acrescido a Consolidação das Leis do trabalho - CLT, por meio da Medida Provisória n ${ }^{0}$ 2.164-41, de 2001); empresa de trabalho temporário ${ }^{13}$; a inserção do regime do Fundo de Garantia do Tempo de Serviço - FGTS, impossibilitando a estabilidade do trabalhado; ampliação de contratos determinado ${ }^{14}$, dentre outros.

Segue o enunciado redacional do art.476-A da Consolidação das Leis do trabalho:

Art. 476-A. O contrato de trabalho poderá ser suspenso, por um período de dois a cinco meses, para participação do empregado em curso ou programa de qualificação profissional oferecido pelo empregador, com duração equivalente à suspensão contratual, mediante previsão em convenção ou acordo coletivo de trabalho e aquiescência formal do empregado, observado o disposto no art. 471 desta Consolidação.

$\S 1^{\circ}$ Após a autorização concedida por intermédio de convenção ou acordo coletivo, o empregador deverá notificar o respectivo sindicato, com antecedência mínima de quinze dias da suspensão contratual.

$\S 2^{\circ} \mathrm{O}$ contrato de trabalho não poderá ser suspenso em conformidade com $\mathrm{o}$ disposto no caput deste artigo mais de uma vez no período de dezesseis meses. $\S 3^{\circ} \mathrm{O}$ empregador poderá conceder ao empregado ajuda compensatória mensal, sem natureza salarial, durante o período de suspensão contratual nos termos do caput deste artigo, com valor a ser definido em convenção ou acordo coletivo.

$\S 4^{\circ}$ Durante o período de suspensão contratual para participação em curso ou programa de qualificação profissional, o empregado fará jus aos benefícios voluntariamente concedidos pelo empregador.

$\S 5^{\circ}$ Se ocorrer a dispensa do empregado no transcurso do período de suspensão contratual ou nos três meses subsequentes ao seu retorno ao trabalho, o empregador pagará ao empregado, além das parcelas indenizatórias previstas na legislação em vigor, multa a ser estabelecida em convenção ou acordo coletivo, sendo de, no mínimo, cem por cento sobre o valor da última remuneração mensal anterior à suspensão do contrato.

$\S 6^{\circ}$ Se durante a suspensão do contrato não for ministrado o curso ou programa

\footnotetext{
$\overline{{ }^{12} \text { Consolidação das Leis do trabalho. Art. 58-A. Considera-se trabalho em regime de tempo parcial aquele cuja duração não }}$ exceda a vinte e cinco horas semanais.

$\S 1^{\circ} \mathrm{O}$ salário a ser pago aos empregados sob o regime de tempo parcial será proporcional à sua jornada, em relação aos empregados que cumprem, nas mesmas funções, tempo integral.

$\S 2^{\circ}$ Para os atuais empregados, a adoção do regime de tempo parcial será feita mediante opção manifestada perante a empresa, na forma prevista em instrumento decorrente de negociação coletiva.

13 Lei no 6.019, de 3 de janeiro de 1974.

${ }^{14}$ Lei no 9.601 , de 21 de janeiro de 1998.
} 
de qualificação profissional, ou o empregado permanecer trabalhando para o empregador, ficará descaracterizada a suspensão, sujeitando o empregador ao pagamento imediato dos salários e dos encargos sociais referentes ao período, às penalidades cabíveis previstas na legislação em vigor, bem como às sanções previstas em convenção ou acordo coletivo.

$\S 7^{\circ} \mathrm{O}$ prazo limite fixado no caput poderá ser prorrogado mediante convenção ou acordo coletivo de trabalho e aquiescência formal do empregado, desde que o empregador arque com o ônus correspondente ao valor da bolsa de qualificação profissional, no respectivo período.

A título de esclarecimento técnico, deve-se ficar clarividente, que o fenômeno da flexibilização e da desregulamentação das relação de trabalho por mais que estejam imbricados são fenômenos distintos (Cairo Jr, 2011).

Na flexibilização há intervenção normativa Estatal, onde este abranda a severidade da normativa trabalhista vigente, permitindo uma maior mobilidade (Cassar, 2011). Exemplo clássico é o art. $7^{\circ}$, VI da Constituição Federal de 1988: "irredutibilidade do salário, salvo o disposto em convenção ou acordo coletivo;".

Já na desregulamentação, uns dos pontos nevrálgicos na político-econômica neoliberal ${ }^{15}$, propugna pela ausência completa do Estado, não havendo a constituição de um patamar jurídico mínimo, permitindo que o empresariado e os trabalhadores formatassem o contrato de trabalho segundo as dinâmicas e necessidades do mercado ${ }^{16}$.

Tem-se na desregulamentação uma supervalorização da proteção decorrente de natureza convencional em detrimento da de natureza legal (Filho, 2007) ${ }^{17}$.

Destaca-se o posicionamento do professor Martins (2009), o qual utiliza a expressão "flexibilização das condições de trabalho" ao invés de "flexibilização do Direito do Trabalho", vislumbrando nesse fenômeno algo natural/salutar, de forma a compatibilizar as regras do Direito do Trabalho com a realidade econômica, tecnológica e social. Ou seja, não visualiza, o professor Martins (2009), a flexibilização como uma forma de precarização das condições de trabalhos, mas a sua conformação com o dinamismo econômico.

\footnotetext{
15 “Milton Friedman afirma que qualquer intervenção no livre jogo do mercado é coercitiva. A intervenção do Estado só se justifica para manter a lei e a ordem, julgar disputas sobre a interpretação da lei, reforçar os contratos, promover a competição, evitar o monopólio. O Estado não deveria intervir para fixar salário mínimo, pois iria distorcer o mercado; em programas de previdência, em razão de que iria provocar injustificada distribuição de renda e um incentivo para os filhos que não viessem a cuidar dos pais idosos (...)" (Martins, 2009, pp. 06-07).

16 “... Desregulamentação significa desprover de normas heterônomas as relações de trabalho. Na desregulação, o Estado deixa de intervir na área trabalhista, não havendo limites na lei para questões trabalhistas, que ficam a cargo da negociação individual ou coletiva" (Martins, 2009, p. 14).

17 "Os defensores da corrente neoliberalista, sob o argumento de que é o excesso de encargos trabalhistas que dificulta a gestão empresarial e o crescimento econômico, têm insistido na tese de que a negociação coletiva deve prevalecer sobre as correspondentes leis, vulnerando a hierarquia das fontes formais de direito e revogando, pela vontade coletiva dos sindicatos, os direitos arduamente conquistados e constitucionalmente garantidos" (Cassar, 2010, p. 41).
} 


\section{PERSPECTIVA DO DIREITO DO TRABALHO NA ÓTICA DA TEORIA DOS SISTEMAS}

\subsection{UMA BREVE INCURSÃO}

Estar a se analisar o direito, de tal sorte, tem-se que estudar a figura do trabalhador dentro de um isolamento jurídico o qual é constituído por uma estrutura normativa de regras e princípios.

Ultrapassar essa realidade constituiria a contaminação do sistema jurídico desvirtuandose em algum hibridismo espúrio. “... o sistema jurídico é operativamente fechado” (Martins, 2009, pp. 13-14), isso a partir de uma visão luhmanniana.

Sendo assim, a lógica sistêmica jurídica opera em termos exclusivamente jurídicos, a partir de uma linguagem binária lícito/ilícito. A partir disso tem o direito a função única de garantir uma expectativa de direito, normativa (Campilongo, 2011).

Com isso extrai-se a seguinte premissa: o sistema jurídico distingue-se do sistema político e do sistema econômico (Campilongo, 2011), o qual possui uma outra lógica, uma outra linguagem, com outras funções.

"O direito positivo moderno trata de todo e qualquer tema ou caso, desde que juridicamente. A partir desse tratamento constrói sua diferença com outros sistemas e opera com elevado grau de complexidade interna" (Campilongo, 2011, p. 88).

A inobservância da premissa supra acarreta atribuir ao direito funções além de suas possibilidades $^{18}$, vindo o mesmo a ser reduzido como técnica do sistema político ou econômico ${ }^{19}$, quedando-se, assim, as fronteiras entre os sistemas e consequentemente anulando ou corrompendo os limites impostos pelo direito, ao demais sistemas. Ter-se-ia a politização do direito e a mercantilização do direito (Campilongo, 2011).

É ululante que o sistema operativo fechado, a qual é o direito, não possui controle sobre os sistemas que estão em seu entorno (político, econômico, das ciências). Da mesma forma, esse ambiente externo ao direito não conseguem suprir o conteúdo típico e único do direito.

Nas palavras do professor Campilongo (2011):

...A unidade, os limites e a especificidade do sistema jurídico são construídos a partir de dentro do próprio sistema jurídico, não são oferecidas pela economia nem pela ciência. A unidade do sistema jurídico é resultante do funcionamento do próprio sistema jurídico. A diferenciação entre o sistema jurídico, a ciência, a economia, a política, é uma diferenciação construída no interior do Direito.

\footnotetext{
18 "Transformar o Direito é o que está ao alcance do sistema jurídico. Pretende transformar, com a norma jurídica, a realidade econômica me parece um ambição, um imperialismo que vai além das possibilidades do Direito" (Campilongo, 2011, p. 94).

19 "Questão interessante e de grande importância para a presente reflexão é o fato de que, a nosso ver, dentre os ramos da ciência jurídica o Direito do Trabalho é, talvez, desde suas origens, o mais interdependente da Economia e dos ciclos econômicos, com todas as suas consequências no mercado de trabalho" (Scabin, 2013, p. 35).
} 
Isto limita muito o socorro que eu possa ter - com critérios hermenêuticos, ou, pelo menos, com critérios juridicamente admissíveis - de elementos exteriores ao sistema jurídico (p. 94).

\subsection{O SISTEMA JURÍDICO TRABALHISTA COMO PROMOTOR DA DIGNIDADE DA PESSOA HUMANA}

No momento que se busca desanuviar qual a função do direito e como desenvolve o seu programa no meio das interações complexas dos sistemas, revela-se com uma clareza solar que não se pode coadunar-se com a lógica econômica do neoliberalismo que prega um discurso de flexibilização dos direitos trabalhistas, quanto mais pactuar a sua desregulamentação.

Não se pode conceber o direito como forma de maximizar os lucros das entidades privadas, mas sim como uma geradora de expectativas de direito geradoras do mínimo existencial ${ }^{20}$ para o trabalhador.

Pele filtro jurídico, não se ver no trabalhador uma mão-de-obra gerador de despesas, como na economia ${ }^{21}$, mas sim, um ser humano, uma pessoa, a qual deve-se buscar uma normatividade geradora de um status de promotora da dignidade humana.

É isso que constitui do Direito do Trabalho, um limite jurídico a racionalidade econômica de forma a impedir que o capital de maximize, que o mercado se expanda de forma que desconsidere a pessoa do trabalhador ${ }^{22}$.

Apesar das crises, é necessário firmar um projeto nacional, para que os Estados não fiquem à mercê das exigências externas, fazendo triunfar os interesses da nação, mesmo num mundo globalizado. A nossa Carta estabelece um Estado forte, intervencionista e regulador. A desregulamentação desmedida e a minimização dos direitos enfraquecem o Estado, único agente capaz de, através de políticas públicas, erradicar as desigualdades sociais que se avolumam em nosso país (Cassar, 2011, p. 290).

\footnotetext{
20 "A garantia de direitos mínimos ao trabalhador faz parte de um conjunto de valores humanos civilizatórios (mínimo existencial), que encontra respaldo no princípio da dignidade da pessoa humana previsto constitucionalmente corno maior patrimônio da humanidade" (Cassar, 2011, p. 29).

21 "O poder econômico, que se intensificou a partir da Revolução Industrial, não é ilegítimo, e pode estar previsto e reconhecido no ordenamento jurídico. O que o legislador deve fazer é coibir os abusos, no sentido de proteger as partes mais fracas da relação jurídica. Nessa ordem de ideias, o Estado deve limitar o poder econômico, coibindo e punindo os abusos: é o que ocorre não só nas relações trabalhistas, mas também nas relações de consumo e nas relações empresariais, para proteção de pequenas e médias empresas" (Scabin, 2013, p. 40).

22 “'(...) Chega-se à não esperada escravidão virtual'. 'O trabalhador competente é aquele que trabalha 24 horas por dia. Realidade triste que precisa de releitura. Escravizou-se o homem ao mercado tecnológico e as redes de informação permitem que o trabalhador se submeta a jornadas desgastantes, ambientalmente prejudiciais à sua saúde, em troca de algo que ainda não se sabe o que é. (...)" (Koller \& Villatore, 2013, p. 12).
} 
Nessa esteira é o pensamento do professor Garcia (2013):

O Direito do Trabalho, portanto, exerce o relevante papel de assegurar patamares mínimos de dignidade e justiça social, impedindo que a busca pela obtenção de lucros e a concorrência acabem impondo níveis inaceitáveis de exploração do trabalho humano, em afronta aos valores magnos da liberdade, justiça, solidariedade e bem comum.

Em conclusão, por qualquer ângulo que se analise a questão, deve-se assegurar a dignidade da pessoa humana, por meio da construção de uma sociedade livre, justa e solidária, com a necessária valorização social do trabalho e o respeito à livre iniciativa... (p. 57).

O discurso da flexibilização das relações de trabalho utiliza argumentos extraído não do sistema jurídico, mas sim de uma lógica mercadológica, extrassistêmicos.

(...) Daí porque as decisões judiciais devem pautar-se por critérios intrassistêmicos e respeitar as expectativas normativas construídas pela jurisprudência, afastando qualquer elemento concernente aos efeitos que determinada decisão possa ocasionar ao erário ..." (Parecer constante da obra coletiva Crédito-Prêmio de IPI. São Paulo, Manole, 2005, pp. 26-27). Trata-se de afirmação importante. Boa parte dos problemas aqui arrolados encontra solução fácil: orientação por critérios extrassistêmicos e propensão para o abandono das expectativas normativas em nome de expectativas cognitivas, motivadas política ou economicamente. Prefiro a cautela do Professor Paulo de Carvalho (Campilongo, 2011, p. 90).

É um discurso falacioso, que prega a redução de gastos com a mão-de-obra, o que geraria a manutenção das vagas de trabalho, ou possibilidade de aumentar a demanda da mesma, além de uma maior capacidade concorrencial (lógica econômica) ${ }^{23}$.

Isso em detrimento de direitos que proporcionam um patamar civilizatório mínimo ao homem. Ou seja, manutenção das vagas de emprego ou mesmo o seu aumento só que rebaixando a um nível que não proporcionara ao trabalhador, sujeito de direito, uma melhor qualidade de vida, mas sim mais trabalho as custas da sua dignidade.

No escólio de Cassar (2010):

A "superexploração" acarreta excesso de trabalho e pouco descanso para repor o mínimo de energia. A recuperação física e mental do trabalho e do estresse

\footnotetext{
23 “...nota-se que a doutrina flexibilizadora habilmente pretende convencer de que favorece o Direito do Trabalho constitucionalizado, quando enfrenta, pela desregulação, a crise" (Filho, 2007, p. 103).
} 
dele decorrente fica esquecida, e este desconforto é agravado pelos salários cujos valores são cada vez mais insuficientes para uma subsistência mínima. Tais práticas são realizadas em nome e em busca da maior lucratividade (p. 41).

E nesse interim, o "capital" aumenta, se expande, se multiplica, na proporção que aumenta-se a desigualdade social, desigualdade entre classes, fomentando a concentração de renda, abstraindo o homem como sujeito, como indivíduo.

Colaciona-se, aqui, a conclusão trazida por um estudo desenvolvido pela Organização Internacional do Trabalho, sobre o aumento vertiginoso do emprego formal, no Brasil, na década de 2000 (Berg, 2010), indo em divergência frontal a afirmação de que a legislação trabalhista seria um obstáculo a criação de empregos, bem como o exagero do processo de flexibilização, recomendando que o governo ao invés de se concentrar em desregulamentar o mercado de trabalho, deveria concentrar os esforços em políticas que incentivassem a formalização da atividade empresarial, seja com incentivos fiscais, simplificação de registros, dentre outros.

The labour market flexibility debate has been exaggerated, at least in the case of Brazil. The experience of the 1990 and 2000 s does not support the claim that labour regulations caused growing informality, and the strong growth in formal jobs in the 2000s at the same time that the minimum wage nearly doubled in real terms, demonstrates that labour laws are not an impediment and that some policies, such as the minimum wage, can be important for stimulating growth and job creation. Rather than focusing on deregulating the labour market, governments should take steps to encourage firms to register their businesses and their workers, either through simplifying registration, lowering taxes or providing incentives to develop high-road competitiveness strategies (Berg, 2010, p. 24).

Destaca-se, novamente, o argumento da professora Vólia Bonfim, que vislumbra a possibilidade de flexibilizar normas trabalhistas, excepcionalmente, em situação de processo de recuperação da "saúde" da sociedade empresarial, perdurando a redução das vantagens trabalhistas nesse interim, tendo em vista o princípio da função social da empresa, onde com o seu fechamento haveria a extinção dos postos de trabalho e consequente prejuízo ao trabalhador (Cassar, 2010).

Ou seja, seria admissível, a flexibilização, temporariamente e excepcionalmente, em situação de dificuldade financeira, exaustivamente comprovado, onde há um real risco de fechamento das atividades empresarias. 


\section{CONSIDERAÇÕES FINAIS}

Ao se falar de direito do trabalho estar-se a estudar uma constelação de direitos elevados a status de norma fundamental propiciadora do desenvolvimento humano, numa esteira de dignificação do homem, em seu sentido mais amplo, galgado num longo processo histórico ${ }^{24}$, no qual se reconhece o valor do trabalho e humaniza-se o sujeito de direito.

O Direito do Trabalho é uma disciplina/sistema autônomo, não constituindo-se em um adendo a economia. Foi criado e constituído com o fito de proteger o trabalhador de forma que o mesmo não fosse mais visto como mercadoria, de equalizar a relação jurídica com o detentor dos meios de produção.

Doravante, as normas trabalhistas galgam uma constelação de direitos ao trabalhador, este naturalmente hipossuficiente, de modo a tentar ofertar um ambiente de igualdade entre as partes, por meio de normas jurídicas, tendo em vista a desigualdade de fato.

Em nenhum ordenamento jurídico, as normas autônomas, fruto das tratativas coletivas, foram normas principais. Ao contrário, sempre foram subsidiárias as normas heterônomas fixadas em Lei, pois o Direito do Trabalho só passa a existir quando da intervenção do Estado na economia (Welfare State), em pró da aclamada igualdade soci2al ${ }^{25}$.

Que o direito tem sua criação e desenvolve-se a partir de necessidades de regular conduta humana tento em vista acontecimentos fáticos, não se questiona. Todavia, ele não é um sistema anexo aos interesses políticos e econômicos, o qual se formatara ao momento. Ele possui linguagem, dinâmica e logica própria, construindo-se e reconstruindo-se dentro do seu próprio sistema.

O caráter axiológico do discurso sobre a flexibilização é de conteúdo meramente mercadológica, que ver o trabalhador como custo/despesa/ônus sem razão justificável.

Acreditar, que no Brasil, com estrutura sindical vigente, estes tenham condições de conseguir promover tratativas, onde as partes estejam no mesmo patamar de igualdade, revertendo em expectativas de condições de trabalho melhores ${ }^{26}$ do que as existentes em Lei é negar a história, falsear a natureza da ciência econômica e enxergar o direito como instrumento

\footnotetext{
${ }^{24} \mathrm{O}$ Direito do Trabalho é uma verdadeira conquista obtida ao longo da história da humanidade, exercendo papel fundamental, ao garantir condições mínimas de vida, assegurando a dignidade da pessoa humana e evitando abusos que o capital e a busca pelo lucro pudessem causar aos membros da sociedade, em especial àqueles que não detêm o poder econômico" (Garcia, 2013, pp. 56-57).

25 "Temos a sensação de que as ideias radicais no sentido de afastamento do Estado do seu papel limitador do poder econômico representam um grande perigo, pois $\mathrm{O}$ eventual retrocesso das conquistas dos trabalhadores e, portanto, a piora das condições de trabalho poderão resvalar em consequências em outras esferas da vida social, inclusive com o aumento da violência que já atinge níveis insuportáveis na atualidade" (Scabin, 2013, p. 41).

26 "Essas negociações, quando ocorrem, podem até mesmo reduzir conquistas econômicas dos trabalhadores para evitar o desemprego; observa-se que o baixo nível de oferta de emprego e o fechamento de postos de trabalho diminuem a receita sindical, ou seja, o sindicato quer a manutenção e ampliação dos empregos, aceitando, inclusive, diminuição de direitos (como redução de jornada de trabalho e salário), o que importa na denominada desregulamentação do contrato de trabalho, ou seja, o fim da intervenção estatal nas condições contratuais de labor" (Lebre, 2013, p. 52).
} 
operacional dos demais sistemas sociais (sem autonomia), incapaz de gerar mudança no seio das interações em sociedade.

O papel reservado aos sindicatos tem sido diminuído e a taxa de desfiliação sindical vem crescendo e a crise dos sindicatos é, igualmente, mundial, isto porque, historicamente, com exceção do Canadá, a maioria dos países teve uma postura sindical embasada na luta de classes, ou seja, no movimento político comunista e anarquista, que foi amplamente difundido e, o mais importante, vivido pelos sindicatos. E o que aconteceu foi o esgotamento desse modelo, fato evidenciado com maior clareza após a queda do muro de Berlim, em 1989, uma vez que a luta ideológica, suscitada entre o capital e o trabalho, acabou dentro do espírito comunista e anarquista. $\mathrm{O}$ que ficou prevalecendo foi a economia de mercado e os mecanismos de capitais, assim sendo, restou aos sindicatos uma revisão da sua postura e a adoção de medidas que tornem menos afligíveis a condição do desempregado. Para uma sociedade que funciona com altos índices de desemprego, os sindicatos são vistos como uma corporação de poucos privilegiados: os que têm um emprego (com as garantias legais e contratuais) (Lebre, 2013, p. 54).

\section{REFERÊNCIAS BIBLIOGRÁFICAS}

Barros, A. M. (2011). Curso do Direito do Trabalho (7ºd.). São Paulo: LTR.

Berg, J. (2010). Laws or luck? Understanding rising formality in Brazil in the 2000s. (O. M. Trabalho, Ed.) Brasília, Brasil. Acesso em 2013, disponível em www.oitbrasil.org.br/sites/ default/files/topic/employment/pub/laws_luck_245.pdf

Cairo Jr, J. (2011). Curso do direito do trabalho (6º ed.). Salvador: Juspodivm.

Campilongo, C. F. (2011). Direito e diferenciação social. São Paulo: Saraiva.

Cassar, V. B. (2010). Princípios Trabalhistas, Novas Profissões, Globalização da Economia e Flexibilização das Normas Trabalhistas. Rio de Janeiro: Impetus.

Cassar, V. B. (2011). Direito do Trabalho (5ºd.). Rio de Janeiro: Impetus.

Delgado, M. G. (2011). Curso do Direito do Trabalho (10 ed.). São Paulo: LTR. 
Filho, J. S. (2007). Sociedade Pós Industrial. Os impactos da globalização na Sociedade, no Trabalho, na Economia e no Estado. Curitiba: Juruá.

Friedman, T., \& Mandelbaum, M. (2012). Éramos nós - a crise americana e como resolvê-la. São Paulo: Companhia das Letras.

Garcia, G. F. (março-abril de 2013). 70 anos da Consolidação das Leis do Trabalho e reforma trabalhista: o debate sobre a desregulamentação e a flexibilização. Revista de Direito do Trabalho, pp. 51-57.

Koller, C. E., \& Villatore, M. A. (2013). A consolidação das leis do trabalho: Institutos em crise e os impactos na sociedade hegemônica e capitalista brasileira. Em J. d. Cavalcante, \& M. A. Villatore, CLT 70 anos de consolidação: uma reflexão social, econômica e jurídica. São Paulo: Atlas.

Lebre, E. A. (2013). A importância do emprego na era da globalização de mercado: considerações sobre a ideologia neoliberal e a reforma da Consolidação das Leis do Trabalho. Em J. d. Cavalcante, \& M. A. Villatore, CLT 70 anos de consolidação: uma reflexão social, econômica e jurídica. São Paulo: Atlas.

Martins, S. P. (2009). Flexibilização das Condições de trabalho (4º ed.). São Paulo: Atlas.

Scabin, R. F. (2013). O Direito do Trabalho como limitador do poder econômico. Em J. d. Cavalcante, \& M. A. Villatore, CLT 70 anos de consolidação: uma reflexão social, econômica e jurídica. São Paulo: Atlas.

\section{CURRICULUM VITAE}

\section{Rocco Antonio Rangel Rosso Nelson}

Especialista em Direito e Cidadania pela Escola Superior do Ministério Público. Especialista em Direito Penal e Criminologia pela Universidade Potiguar. Mestre em Direito Constitucional pela UFRN. Ex-professor do curso de direito do Centro Universitário FACEX. Professor de Direito do Instituto Federal do Rio Grande do Norte - IFRN, campus João Câmara. rocconelson@hotmail.com 